(some repeated), only 95 date from 1984 onwards, and of the 11 from 1985 one (page 312) is reported as still being "in press."

Overall my niggles are minor compared with the excellence of this book. It should be read by all who practise twentieth century obstetrics and gynaecology. The cost may prevent everyone from buying it, but should prevent no one from reading it.

P BROMWICH

\section{Wide of the mark}

Primary Health Care 2000. Ed J Fry, J C Hasler. (Pp 400; figs; £25.) Edinburgh: Churchill Livingstone, 1986. ISBN 0-443-03315-3.

The development of primary health care has been the most important policy development in international health over the past 25 years. Its approach, as defined in the Alma Ata Declaration of the World Health Organisation and the United Nations Children's Fund (WHO-UNICEF) in 1978, emphasises the importance of equitable access; community participation; an appropriate balance between prevention, promotion, curative care, and rehabilitation; the use of locally appropriate technologies; and a multisectoral approach to the provision of health care. Objective and critical reviews of the successes and failures of attempts to implement this policy (especially in national or large scale programmes) are urgently needed, and, although the aims of this book are not stated explicitly, I presume that it sets out to achieve this.

Common issues that span all countries are considered in the first section, and then follow a series of brief reviews of primary health care in selected countries. I approached this new book with interest but was very disappointed by it. It resembles the curate's egg: bad in parts and not so bad in others, but never a substantial meal.

The book's audience is not clear. It attempts to discuss primary health care in both industrialised and non-industrialised countries but has a heavy bias towards the former. Most of the 31 authors are men, medical doctors from Western Europe and North America, and this is reflected in the content. Even in the "common issues" section authors have tended to discuss each issue in their own context and then add a few brief comments about developing countries. The exception to this is the last chapter, by Professor Morley, which as a result seems out of place. Although the 1978 WHO-UNICEF definition of primary health care is given in chapter 1 , the overall emphasis of the book is on first contact medical care provided by physicians. This is even true in many of the chapters

\section{Contributors}

J K ARONSON is clinical reader in clinical pharmacology at the Radcliffe Infirmary, Oxford.

PAul Bowden is a consultant forensic psychiatrist at the Maudsley Hospital, London.

J E MACGREGOR, now retired, was formerly senior lecturer in pathology at the University of Aberdeen.

$\mathrm{P}$ BRomwich is a clinical lecturer in obstetrics and gynaecology at the John Radcliffe Hospital, Oxford.

DAvid A Ross is a lecturer in health care epidemiology at the London School of Hygiene and Tropical Medicine. and statements about countries where little primary health care or even primary medical care is provided by doctors.

Some chapters are so superficial that it is difficult to think of anyone who could gain much from reading them. Chapter 3, on economics, politics, and society, is a good example: the whole issue of inequalities in health and health care is dismissed in seven lines, which start "Neither health nor health services can ever be shared equally" (p 34). Fortunately some of the later chapters in this section are much better. Chapter 7 on community participation in British general practice is particularly interesting for it deals with both the successes and the problems of attaining true community participation.

The book suffers greatly from having so many authors, and there is frequent repetition of statements about complex issues that are never discussed adequately - for example, the relation between health and population growth. Several chapters have annoying editorial or typographical errors, especially chapter 3 . In the section on national perspectives, though the quality of the various chapters differs considerably, none gives more than a superficial presentation in its eight to 19 pages, and the chapter on South Africa only just falls short of being a total whitewash.

Overall I think that this book falls between two stools, neither giving a satisfactory analysis of primary health care in industrialised countries nor making a useful contribution to the issue in nonindustrialised countries.

DAvid A Ross

\section{In brief . . .}

Written for a non-medical audience whose "wilderness" and watersport activities put them at risk, Hypothermia, Frostbite, and Other Cold Injuries: Prevention, Recognition, and Prehospital Treatment by J A Wilkerson, C C Bangs, and J S Hayward ( $\$ 7.50$ paperback; Seattle, Washington: The Mountaineers, 1986, ISBN 0-89886-024-5. Obtainable from Cordee, 3a De Montfort Street, Leicester LE1 7HD) this is a compact publication that fills a void in the publications on exposure to cold. Its competitor must be Evan Lloyds's Hypothermia and Cold Stress, published this year by Croom Helm at almost four times the price.

Lay readers of this volume will gain more knowledge on the subject than most doctors possess. Temperature physiology is covered succinctly in a dogmatic but lucid style and well related to practical problems. The message that hypothermia should be avoided, not treated, is stated repeatedly, and practical advice is given on how to achieve this. The chapter on protective clothing is pure gold, covering all the snags known to sharp end users but ignored by or still baffling manufacturers. (The Americans still use CLO units, but European garments are marked in TOG units.) Immersion hypothermia is particularly well covered, with clear guidance on the risks and how to minimise them. Surprisingly, the circulatory hazards of releasing the hydrostatic squeeze on rescue and the importance of a horizontal lift (if practical) are omitted.

The mountaineer will find all he needs to know on frostbite here, although he may cringe when reading of male American climbers getting genital damage after contact with metal trouser zippers on micturition. Helicopter evacuation is omitted, as is guidance on when to carry or when to stabilise and walk out. Rescue teams find this a searching problem, especially when dealing with multiple casualties.

An excellent little publication, but exercise caution when lending it to patients who face these hazards. It may not come back.

\section{Correction}

New technology spurs demarcation debates

We regret that an error occurred in the first line of this book review (4 October, p 878). It should have read "Interventional radiology epitomizes the evolution of new disciplines..." 